ARTICLE

Received 3 Mar 2013 | Accepted 29 Jul 2013 | Published 27 Aug $2013 \quad$ DOI: 10.1038/ncomms3365

\title{
A zero-strain layered metal oxide as the negative electrode for long-life sodium-ion batteries
}

Yuesheng Wang ${ }^{1, \star}$, Xiqian $\mathrm{Yu}^{2, \star}$, Shuyin $\mathrm{Xu}^{1}$, Jianming Bai ${ }^{2}$, Ruijuan Xiao ${ }^{1}$, Yong-Sheng $\mathrm{Hu}^{1}$, Hong $\mathrm{Li}^{1}$, Xiao-Qing Yang ${ }^{2}$, Liquan Chen $^{1} \&$ Xuejie Huang ${ }^{1}$

Room-temperature sodium-ion batteries have shown great promise in large-scale energy storage applications for renewable energy and smart grid because of the abundant sodium resources and low cost. Although many interesting positive electrode materials with acceptable performance have been proposed, suitable negative electrode materials have not been identified and their development is quite challenging. Here we introduce a layered material, $\mathrm{P} 2-\mathrm{Na}_{0.66}\left[\mathrm{Li}_{0.22} \mathrm{Ti}_{0.78}\right] \mathrm{O}_{2}$, as the negative electrode, which exhibits only $\sim 0.77 \%$ volume change during sodium insertion/extraction. The zero-strain characteristics ensure a potentially long cycle life. The electrode material also exhibits an average storage voltage of $0.75 \mathrm{~V}$, a practical usable capacity of ca. $100 \mathrm{mAhg}^{-1}$, and an apparent $\mathrm{Na}^{+}$diffusion coefficient of $1 \times 10^{-10} \mathrm{~cm}^{-2} \mathrm{~s}^{-1}$ as well as the best cyclability for a negative electrode material in a half-cell reported to date. This contribution demonstrates that $\mathrm{P} 2-\mathrm{Na}_{0.66}$ $\left[\mathrm{Li}_{0.22} \mathrm{Ti}_{0.78}\right] \mathrm{O}_{2}$ is a promising negative electrode material for the development of rechargeable long-life sodium-ion batteries.

\footnotetext{
${ }^{1}$ Key Laboratory for Renewable Energy, Beijing Key Laboratory for New Energy Materials and Devices, Beijing National Laboratory for Condensed Matter Physics, Institute of Physics, Chinese Academy of Sciences, Beijing 100190, China. ${ }^{2}$ Chemistry Department, Brookhaven National Laboratory, Upton, New York 11973, USA. * These authors contributed equally to this work. Correspondence and requests for materials should be addressed to Y.-S.H. (email: yshu@aphy.iphy.ac.cn) or to R.X. (email: rjxiao@aphy.iphy.ac.cn).
} 
W ith the tremendous development of renewable energies such as solar and wind power, the smooth integration of these energies into the grid, thus improving the grid reliability and utilization, critically needs large-scale energy storage systems with long-life, high efficiency, high safety and low $\operatorname{cost}^{1,2}$. Among the various energy storage technologies, electrochemical approach represents one of the most promising means to store electricity in large-scale because of the flexibility, high energy conversion efficiency and simple maintenance ${ }^{2-4}$. Because of the highest energy density among practical rechargeable batteries, lithium-ion batteries have been widely used in portable electronic devices and would undoubtedly be the best choice for (hybrid) electric vehicles ${ }^{5,6}$. However, the high cost and limited resources of lithium have caused some concerns of using lithium-ion batteries in the large-scale energy storage systems $^{7-15}$. In this background, room-temperature sodium-ion batteries with lower energy density compared with lithium-ion batteries have been reconsidered particularly for such large-scale applications ${ }^{16-24}$, where cycle life and cost are the more essential factors than energy density, in both academic and industrial communities, owing to the abundant sodium resources and potentially low cost as well as the similar 'rocking-chair' sodium storage mechanism to that of lithium.

Searching for suitable electrode materials to satisfy the longterm stability requirement is an important step to realize the large-scale energy storage. The electrode materials with small volume change during guest ion insertion and extraction, for example, zero-strain characteristics, have attracted great attention because of the potentially excellent long cycling performance. A typical example of zero-strain ${ }^{25,26}$ negative electrode material is the well-known spinel $\mathrm{Li}_{4} \mathrm{Ti}_{5} \mathrm{O}_{12}$ via a two-phase storage mechanism $\left(\mathrm{Li}_{4} \mathrm{Ti}_{5} \mathrm{O}_{12}\right.$ and $\mathrm{Li}_{7} \mathrm{Ti}_{5} \mathrm{O}_{12}$, the volume change between them is $\sim 0.2 \%$ ), which has been demonstrated for thousands of cycles in lithium-ion batteries ${ }^{27}$, indeed showing the advantage of using zero-strain material for long-term stable cycling. So far to the best of our knowledge, no zero-strain negative electrode material is available for sodium-ion batteries although a few types of negative electrode materials have been reported to be active in sodium-ion batteries ${ }^{9-12,28-41}$. Among the available negative electrode materials, hard carbon shows the best overall storage performance in terms of high storage capacity and good cycling. However, most of the capacity is located at the voltage below $0.1 \mathrm{~V}$, which is too close to the sodium plating voltage, causing potential safety concerns, especially at fast charging rates or overcharging. Several oxides such as $\mathrm{Na}_{2} \mathrm{Ti}_{3} \mathrm{O}_{7}$ and alloys (Sn or $\mathrm{Sb}$ ) have shown high storage capacity ${ }^{30,33-35}$, but would not be suitable for long-life batteries owing to the large volume change during sodium insertion and extraction ${ }^{39}$, which is undesirable to the structural stability.

Recently, several layered $\mathrm{Na}_{x} \mathrm{MO}_{2}$ (M: 3d transition metals, TMs) compounds have been proposed as positive electrode materials for sodium-ion batteries ${ }^{42-52}$. It has also been demonstrated that P2-type materials show better storage performance than that of O3-type materials (Note that the notations of P2 and O3 were defined by Delmas et al. ${ }^{53}$, they refer to different ways of the stacking of the oxygen layer, for example, ABBA for P2, $\mathrm{ABCABC}$ for $\mathrm{O} 3$ and so on $)^{46}$. In the case of $\mathrm{P} 2$-type materials, the value of ' $x$ ' in $\mathrm{Na}_{x} \mathrm{MO}_{2}$ is less than 1 and typically $2 / 3$, leaving many vacancies in the alkali layer. These vacancies could be filled again by sodium insertion, and thus P2-type materials could be used as negative electrodes if the operation potential of TM redox couple is suitable. Among 3d TMs, some Ti oxides show lower redox potential compared with $\mathrm{Mn}, \mathrm{Fe}, \mathrm{Co}$ and $\mathrm{Ni}$ oxides ${ }^{25-27,30-32}$; however, $\mathrm{TiO}_{6}$ octahedral is not stable in air in layered $\mathrm{Na}_{2 / 3} \mathrm{TiO}_{2}$ because of the $\mathrm{Ti}^{3+}$ environment (note that the electrochemical behaviour of $\mathrm{O} 3-\mathrm{NaTiO}_{2}$ which is not stable in air has been reported in 1980s (ref. 54). Only $0.3 \mathrm{Na}$ $\left(78 \mathrm{mAh}^{-1}\right)$ can be reversibly extracted and inserted in this O3-type material.). Introducing ions with lower valence state into Ti sites may increase the valence state of $\mathrm{Ti}^{3+}$ to $\mathrm{Ti}^{4+}$ without destroying the layered structure, and may result in the stability of the new compound. Considering the similar ionic radius of $\mathrm{Li}^{+}$and $\mathrm{Ti}^{4+}$, we choose $\mathrm{Li}$ as a candidate doping element for $\mathrm{Na}_{2 / 3} \mathrm{TiO}_{2}$. Following this idea, we explored the sodium storage performance of $\mathrm{Na}_{0.66}\left[\mathrm{Li}_{0.22} \mathrm{Ti}_{0.78}\right] \mathrm{O}_{2}$ in which $\mathrm{Li}$ and Ti occupy the TM layer, and found the sodium ionic conductivity to be $0.035 \mathrm{~S} \mathrm{~cm}^{-1}$ at $300^{\circ} \mathrm{C}$ (ref. 55). It is expected that $0.34 \mathrm{Na}$ per formula unit can be inserted into this host.

Here we report a zero-strain negative electrode material for sodium-ion batteries, the P2-type layered $\mathrm{Na}_{0.66}\left[\mathrm{Li}_{0.22} \mathrm{Ti}_{0.78}\right] \mathrm{O}_{2}$, which exhibits an average storage voltage of $0.75 \mathrm{~V}$ and a reversible capacity of $116 \mathrm{mAhg}^{-1}$. The most desirable property is that the volume change during sodium insertion and extraction is $\sim 0.77 \%$, showing the zero-strain characteristics, thereby ensuring potentially long cycle life as demonstrated by over 1,200 repeated cycles with capacity retention of $75 \%$.

\section{Results}

Structure of $\mathrm{Na}_{0.66}\left[\mathrm{Li}_{0.22} \mathrm{Ti}_{0.78}\right] \mathrm{O}_{2}$. This compound was prepared by a simple solid-state reaction using precursors of $\mathrm{Na}_{2} \mathrm{CO}_{3}, \mathrm{Li}_{2} \mathrm{CO}_{3}$ and $\mathrm{TiO}_{2}$. Fig. la shows the synchrotron X-ray
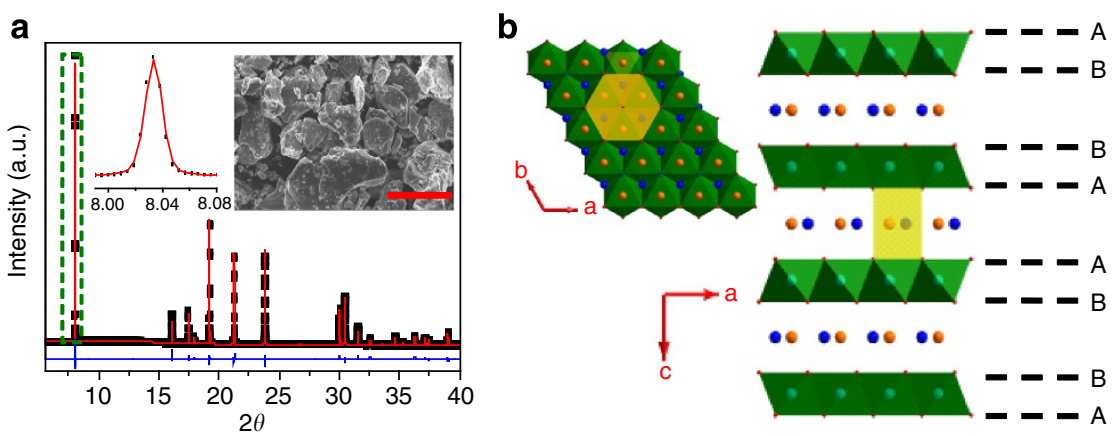

Figure 1 | Structure of $\mathbf{P 2}-\mathbf{N a}_{\mathbf{0 . 6 6}}\left[\mathbf{L i}_{\mathbf{0 . 2 2}} \mathbf{T i}_{\mathbf{0 . 7 8}}\right]_{\mathbf{2}}$. (a) Synchrotron XRD pattern and Rietveld refinement of the as-prepared $\mathrm{Na}_{0.66}\left[\mathrm{Li}_{0.22} \mathrm{Ti}_{0.78}\right] \mathrm{O}_{2}$ sample. The red (black) line represents the experimental (calculated) data. The residual discrepancy is shown in blue. The refinement is preformed in the $\mathrm{P}_{3} / \mathrm{mmc}$ space group. The inset is the typical scanning electron micrograph of the as-prepared sample (scale bar is $10 \mu \mathrm{m}$ ). (b) Schematic illustration of the hexagonal $\mathrm{Na}_{0.66}\left[\mathrm{Li}_{0.22} \mathrm{Ti}_{0.78}\right]_{2}$ projected in $a-c$ plane (left top is projected in $a-b$ plane). Symbols $\mathrm{A}$ and $\mathrm{B}$ refer to the different oxygen layers. The green layer represents the $\mathrm{Ti}(\mathrm{Li}) \mathrm{O}_{2}$ layer and orange ( $2 \mathrm{~b}$ site) or blue ( $2 \mathrm{~d}$ site) bullets refer to $\mathrm{Na}$ ions that occupy the trigonal prismatic sites between two $\mathrm{Ti}(\mathrm{Li}) \mathrm{O}_{2}$ layers. 
diffraction (XRD) pattern and the Rietveld refinement of the resulting material. All of the diffraction peaks are in good agreement with the JCPDS No. 52-0689 and is isostructural with a typical P2-type $\mathrm{Na}_{2 / 3} \mathrm{CoO}_{2}$ (ref. 44), indicative of a pure P2 phase material. The Rietveld refinement within a space group of hexagonal $\mathrm{P}_{3} / \mathrm{mmc}$ gives the lattice parameters of $a=b=2.9643(1) \AA, c=11.1351(4) \AA$ and $V=84.73 \AA^{3}$, which are in good agreement with the $a b$ initio simulation (detailed information is shown in Supplementary Table S1). According to the refinement, a schematic structure of the $\mathrm{Na}_{0.66}\left[\mathrm{Li}_{0.22} \mathrm{Ti}_{0.78}\right] \mathrm{O}_{2}$ is presented in Fig. 1b. Different from O3-type material, the repulsive Coulomb interaction of the AA-type oxygen stacking gives rise to a larger interlayer of 5.5636(5) $\AA$, which was deduced from (002) peak. In this structure, the larger sodium ions occupy the trigonal prismatic sites in one layer, whereas smaller $\mathrm{Li}$ and $\mathrm{Ti}$ ions co-occupy the neighbouring layer. In addition, some of $\mathrm{Na}$ ions (0.425) occupy the $2 \mathrm{~d}$ site sharing the edges with the $\mathrm{TiO}_{6}$ octahedra, whereas others $(0.211)$ occupy the $2 \mathrm{~b}$ site sharing two faces with the $\mathrm{TiO}_{6}$ octahedra (Supplementary Table S1). This situation is similar to other P2 materials ${ }^{44,48,49,56}$. The morphology of the sample was investigated with scanning electron microscopy. As shown in the inset of Fig. 1a, the distribution of particle size of the as-prepared sample is in the range of $10-15 \mu \mathrm{m}$.

Sodium storage performance. The sodium storage performance of $\mathrm{P} 2-\mathrm{Na}_{0.66}\left[\mathrm{Li}_{0.22} \mathrm{Ti}_{0.78}\right] \mathrm{O}_{2}$ in sodium half cells is shown in Fig. 2a. In the first discharge curve, it can be seen that the voltage drops quickly to $1.2 \mathrm{~V}$ and then decreases monotonically from 1.2 to $0.4 \mathrm{~V}$, indicating the sodium insertion through a solid-solution reaction ${ }^{44}$. (note that the reason of choosing the cut-off voltage of $0.4 \mathrm{~V}$ is that it delivers the best cyclic performance as shown in Supplementary Fig. S1). This is further supported by the synchrotron in situ XRD results as discussed later. This behaviour is different from other P2-type electrodes, where multiple plateaus were usually observed during sodium extraction/insertion which is related to a series of phase transitions (sodium/vacancy ordering or charge ordering) $)^{9-12,44,48}$. The random distribution of $\mathrm{Li}$ in the TM layer, which is deduced from the high resolution XRD pattern that does not exhibit any superstructure peaks ${ }^{49}$, could be responsible for such sodium storage mechanism in the $\mathrm{P} 2-\mathrm{Na}_{0.66}\left[\mathrm{Li}_{0.22} \mathrm{Ti}_{0.78}\right] \mathrm{O}_{2}$. The other feature of interest is that the average sodium storage voltage is ca. $0.75 \mathrm{~V}$, higher than that of layered $\mathrm{Na}_{2} \mathrm{Ti}_{3} \mathrm{O}_{7}(0.3 \mathrm{~V})^{30}$ which is close to the sodium plating voltage, making it much safer. The average potential of sodium insertion into $\mathrm{P} 2-\mathrm{Na}_{x}\left[\mathrm{Li}_{0.22} \mathrm{Ti}_{0.78}\right] \mathrm{O}_{2} \quad(0.66 \leq x \leq 1)$ can be estimated as:

$$
V_{\text {ave }}=-\frac{E_{\mathrm{NaLi}_{0.22} \mathrm{Ti}_{0.78} \mathrm{O}_{2}}-E_{\mathrm{Na}_{0.66} \mathrm{Li}_{0.22} \mathrm{Ti}_{0.78} \mathrm{O}_{2}}-0.34 E_{\mathrm{Na}}}{0.34 e}
$$

in which $E$ is the theoretical total energy per f.u. obtained from density functional theory (DFT) calculations. Entropy and temperature effects are not considered. The calculated average potential is $0.47 \mathrm{~V}$, which is slightly lower than the experimental value. The difference may come from the absence of kinetic effects in the calculations, where the potential we obtained is thermodynamic equilibrium voltage. The reversible capacity is $116 \mathrm{mAh} \mathrm{g}^{-1}$, corresponding to $0.38 \mathrm{Na}$ insertion per formula unit. This value is slightly higher than the available vacancy $(0.34)$ in the $\mathrm{Na}_{0.66}\left[\mathrm{Li}_{0.22} \mathrm{Ti}_{0.78}\right] \mathrm{O}_{2}$. Note that the inductively coupled plasma-optical emission spectrometer result shows the real composition of the resulting material is $\mathrm{Na}_{0.63}\left[\mathrm{Li}_{0.22} \mathrm{Ti}_{0.78}\right] \mathrm{O}_{1.98}$, leaving some sodium and oxygen vacancies. In this case, it will allow $0.37 \mathrm{Na}$ insertion into the host, corresponding to a capacity of $116 \mathrm{mAhg}^{-1}$, which is close to what we obtained. An irreversible capacity loss was observed in the first cycle, which could be ascribed to the formation of solid electrolyte interphase layer (SEI) when discharged to a lower voltage (Supplementary Fig. S2). This is a common phenomenon in the lithium-ion batteries for a low voltage negative electrode. The electrode can also be cycled well at $60^{\circ} \mathrm{C}$ (Supplementary Fig. S3).

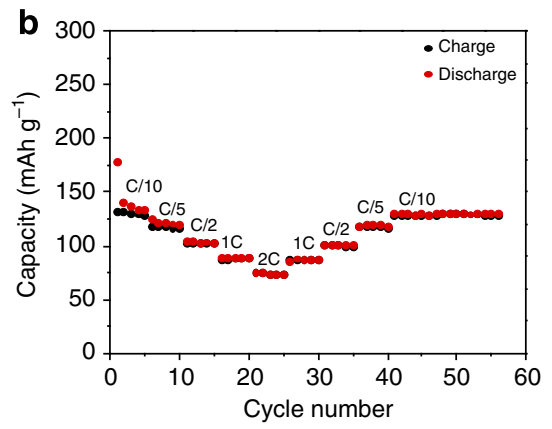

d

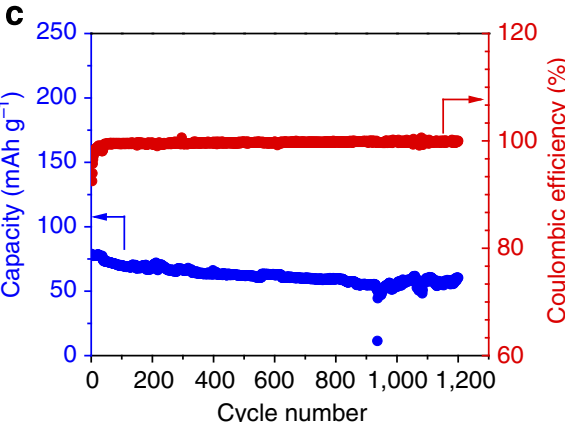

Figure 2 | Sodium storage performance of $\mathbf{P 2}-\mathbf{N a}_{\mathbf{0 . 6 6}}\left[\mathbf{L i}_{\mathbf{0 . 2 2}} \mathbf{T i}_{\mathbf{0 . 7 8}} \mathbf{O O}_{\mathbf{2}}\right.$ electrodes. (a) The 1st, 50th and 200th discharge/charge curves at a current rate of $\mathrm{C} / 10\left(10.6 \mathrm{~mA} \mathrm{~g}^{-1}\right)$ in the voltage range of 0.4 and $2.5 \mathrm{~V}$ versus $\mathrm{Na}^{+} / \mathrm{Na}$. (b) Rate capability. The capacity versus cycle number at various current rates. (c) Long-term cycling performance. The capacity and Coulombic efficiency versus cycle number at a current rate of $2 \mathrm{C}$. (d) Discharge profiles of $\mathrm{Na}_{0.66}\left[\mathrm{Li}_{0.22} \mathrm{Ti}_{0.78}\right] \mathrm{O}_{2} / / \mathrm{Na}_{3} \mathrm{~V}_{2}\left(\mathrm{PO}_{4}\right)_{3} / \mathrm{C}$ sodium-ion full cell at various rates (inset is the cyclic performance of the full cell at $1 \mathrm{C}$ rate). 
The rate capability of the $\mathrm{Na}_{0.66}\left[\mathrm{Li}_{0.22} \mathrm{Ti}_{0.78}\right] \mathrm{O}_{2}$ electrode was also evaluated in a sodium cell. It can be seen from Fig. $2 \mathrm{~b}$ that the reversible capacities are $116,106,90,77$ and $62 \mathrm{mAh} \mathrm{g}^{-1}$ at constant current rates of $\mathrm{C} / 10, \mathrm{C} / 5, \mathrm{C} / 2,1 \mathrm{C}$ and $2 \mathrm{C}$, respectively. The capacity retention at $2 \mathrm{C}$ is $53.4 \%$ of the initial capacity. It should be noted that these values were obtained from the sample with pretty large particle size $(10-15 \mu \mathrm{m})$ and without any special efforts such as carbon-coating and nanosizing. We believe the rate capability could be further optimized. The most appealing property of this material is the excellent long-term cyclic stability. As shown in Fig. $2 \mathrm{c}$ and Supplementary Fig. S4, the $\mathrm{Na}_{0.66}$ $\left[\mathrm{Li}_{0.22} \mathrm{Ti}_{0.78}\right] \mathrm{O}_{2}$ electrode exhibits over 1,200 cycles with capacity retention of $75 \%$ at a current rate of $2 \mathrm{C}$ (a very small capacity decay of $0.02 \%$ per cycle). The Coulombic efficiency after initial cycles can reach nearly $100 \%$. (note that the low Coulombic efficiency at initial cycles is probably related to the electrolyte degradation and/or unstable metallic sodium electrode ${ }^{14,21,57}$ ). Both parameters are crucial for a practical application. As far as we know, P2- $\mathrm{Na}_{0.66}\left[\mathrm{Li}_{0.22} \mathrm{Ti}_{0.78}\right] \mathrm{O}_{2}$ exhibits the best cycling performance demonstrated so far among all reported negative electrode materials for sodium-ion batteries ${ }^{28-36}$.

A sodium-ion full cell was also demonstrated using $\mathrm{P} 2-\mathrm{Na}_{0.66}$ $\left[\mathrm{Li}_{0.22} \mathrm{Ti}_{0.78}\right] \mathrm{O}_{2}$ as negative electrode and $\mathrm{Na}_{3} \mathrm{~V}_{2}\left(\mathrm{PO}_{4}\right)_{3} / \mathrm{C}$ as positive electrode. In order to obtain a practical usable capacity for full cell, the electrode was also cycled in a narrow voltage range of $0.4-1.4 \mathrm{~V}$ (Supplementary Fig. S5). It can be seen that a reversible capacity of $c a .100 \mathrm{mAhg}^{-1}$ can be achieved. Preliminary results show that the full cell gives rise to an average operating voltage at $\sim 2.5 \mathrm{~V}$ and appropriate rate and cycling performance (Fig. 2d). The performance can be further enhanced by optimization of both electrodes and their weight ratio.

\section{Discussion}

To understand the structure evolution during sodium insertion and extraction, we performed the synchrotron electrochemical in situ XRD experiment and the results are plotted in Fig. 3 (also see Supplementary Fig. S6). No new peaks beyond P2 structure were observed at the beginning of sodium insertion, but only some slightly shift to higher two theta angles and others to lower angle upon sodium insertion. In particular, the shift of the (002) peak is very small. It can be observed that a solid-solution reaction apparently occurs at the initial discharge until $0.55 \mathrm{~V}$, evidenced by a continuous peak shift and lattice constant variation (Supplementary Fig. S7), with the structure being identified with a single P2 phase. However, along with

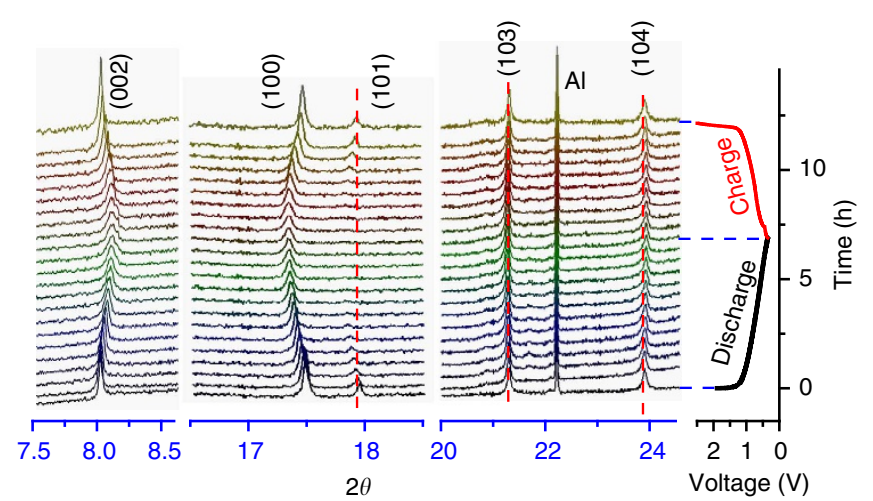

Figure 3 | Structure evolution of electrochemical sodiation. In situ XRD patterns collected during the first discharge/charge of the $\mathrm{Na}$ / $\mathrm{Na}_{0.66}\left[\mathrm{Li}_{0.22} \mathrm{Ti}_{0.78}\right] \mathrm{O}_{2}$ cell under a current rate of $\mathrm{C} / 7$ at voltage range between 0.4 and $2.5 \mathrm{~V}$. further sodium insertion, it is interesting to find the shape of (002) peak becomes asymmetry with a broad feature, which is indicative of multiphase or domains. In order to make this point clear, a long-time XRD measurement was carried out on the finally discharged electrode (discharged to $0.4 \mathrm{~V}$, sample was scratched off from the electrode and loaded into capillary) and a high resolution XRD pattern was obtained (Fig. 4a). It can be seen that the resulting XRD pattern can be fitted very well with two $\mathrm{P} 2-\mathrm{Na}_{\mathrm{x}} \mathrm{Li}_{0.22} \mathrm{Ti}_{0.78} \mathrm{O}_{2}$ phases with very similar cell parameters: $(a=b=2.9932(0) \AA, c=10.9538(3) \AA)$ and $(a=b=3.0066(1) \AA$, $c=10.9087(5) \AA)$. The discrepancy between these two phases is mainly caused by the Na occupancy difference within the unit cell (the detailed structure information is presented in Supplementary Table S1). One may doubt that this result originated from the experimental technique error because it is well-known that the reduced Ti-based oxides are very easy to get oxidized, either through contact with air or by reacting with organic solvent ${ }^{54}$. In order to avoid the sample "change" during ex situ sample preparation, a newly developed technique based on a combination of chemical sodiation and in situ synchrotron XRD was further performed. The most advantage of this new technique is that during the X-ray measurement the sample in capillary will not be exposure to air. The in situ XRD patterns collected during chemical sodiation are presented in Fig. 5 . The sodiation proceeds very quickly, evidenced by the continuous shift of the (002) peak at the initial chemical sodiation stage $(0-45 \mathrm{~min})$. Further $\mathrm{Na}$ insertion causes a new phase emerge, reflected by the asymmetry of the (002) peak. The similar phase transition behaviour during chemical sodiation further supports our electrochemical in situ XRD results. After chemical sodiation for $60 \mathrm{~h}$, we collected the XRD pattern with a high resolution as shown in Fig. 4b. Similar as the abovementioned ex situ result (discharged $0.4 \mathrm{~V}$ sample), the pattern of the fully sodiated product can also not be refined with a single-phase model. After carefully examining the XRD pattern, a multiphase (same space group: $\mathrm{P}_{3} / \mathrm{mmc}$ ) with gradient lattice variation model ${ }^{58}$ was adopted in the Rietveld refinement and a very good refinement result was obtained (Fig. $4 \mathrm{~b}$ and Supplementary Table S1). The major difference between these similar phases is originated from the sodium occupancy difference at the $2 \mathrm{~d}$ site, which may be mostly due to the inhomogeneous reaction during chemical sodiation (non equilibrium process) compared with electrochemical reaction. The average $\mathrm{Na}$ molar concentration estimated from the refinement is $\sim 0.945$, slightly smaller than the ICP result $\left(\mathrm{Na}_{0.99}\left[\mathrm{Li}_{0.22} \mathrm{Ti}_{0.78}\right] \mathrm{O}_{1.98}\right)$, probably owing to the refinement error or non-crystallized phase that cannot be detected by $\mathrm{XRD}^{59}$. On the basis of this, we can conclude that the final discharge or sodiated product actually consists of several P2 phases which have slight different $\mathrm{Na}$ contents and occupations $(2 \mathrm{~b}, 2 \mathrm{~d})$. It should be pointed out that the amount of $\mathrm{Na}$ occupation at $2 \mathrm{~b}$ site is decreased along with more and more $\mathrm{Na}$ insertion. Upon $\mathrm{Na}$ insertion, from an electrostatic point of view, $\mathrm{Na}$ will preferentially occupy the $2 \mathrm{~d}$ site in the interslab because $2 \mathrm{~d}$ site shares the edges with the $\mathrm{TiO}_{6}$ octahedra and has less electrostatic repulsion between $\mathrm{Na}$ and $\mathrm{TiO}_{6}$ octahedra $44,48,49,56$. After a large amount of Na occupies the $2 \mathrm{~d}$ site, a part of $\mathrm{Na}$ at the $2 \mathrm{~b}$ site sharing two faces with the $\mathrm{TiO}_{6}$ octahedra will be pushed to the $2 \mathrm{~d}$ site due to the strong electrostatic repulsion between $2 \mathrm{~b}$ and $2 \mathrm{~d}$ sites (a scheme has been shown in Supplementary Fig. S8).

These observations indicate that the sodium insertion in this material is like quasi-solid-solution reaction, which is in good agreement with the shape of discharge curve. After $0.34 \mathrm{Na}$ insertion, it is interesting to note that the $\mathrm{P} 2$ phases can still be maintained according to our in situ and ex situ XRD results. On the basis of the refinement results as shown in Table 1 , it can be seen that the $c$ axis is decreased by $2.03 \%$, whereas the $a(b)$ axis is 

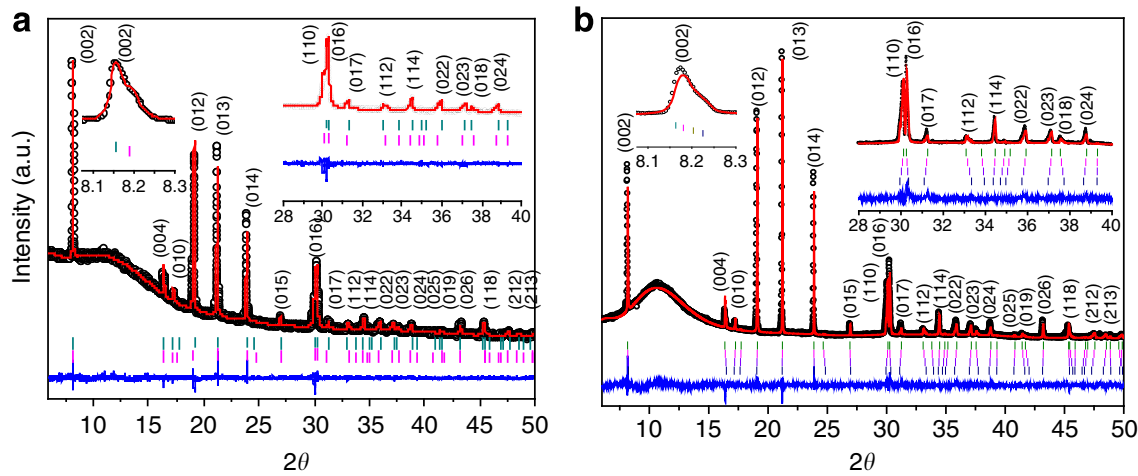

Figure 4 | Synchrotron XRD patterns and Rietveld refinements. The XRD patterns of (a) the $\mathrm{Na}_{0.66}\left[\mathrm{Li}_{0.22} \mathrm{Ti}_{0.78}\right] \mathrm{O}_{2}$ electrode discharged to $0.4 \mathrm{~V}$ and (b) the $\mathrm{Na}_{0.66}\left[\mathrm{Li}_{0.22} \mathrm{Ti}_{0.78}\right] \mathrm{O}_{2}$ sample after chemical sodiation for $60 \mathrm{~h}$. They show that the final electrochemically and chemically sodiated samples are actually a mixture of several P2 phases, which may be due to the inhomogeneity of the Na occupancy. The red (black) line represents the experimental (calculated) data. The residual discrepancy is shown in blue. The refinement is preformed in the $\mathrm{P}_{3} / \mathrm{mmc}$ space group. The Bragg peak positions are shown by the vertical lines.

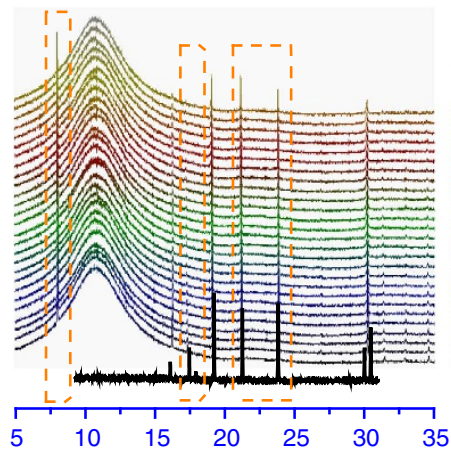

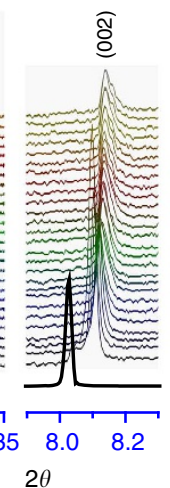

$2 \theta$
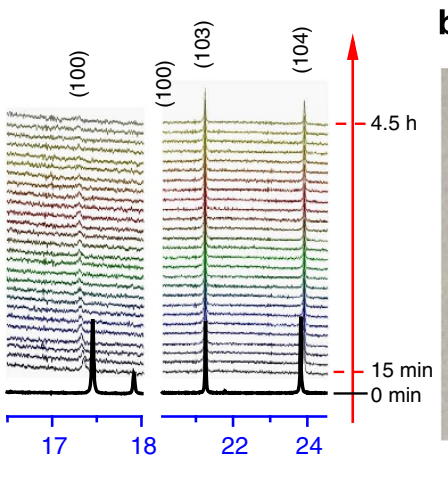

b

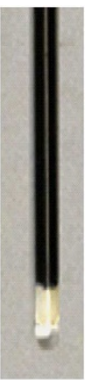

Figure 5 | Structure evolution of chemical sodiation. (a) In situ XRD patterns collected during the chemical sodiation of the $\mathrm{Na}_{0.66}\left[\mathrm{Li}_{0.22} \mathrm{Ti}_{0.78}\right]_{\mathrm{O}_{2}}$ using sodium-biphenyl-DME reducing agent. (b) A scheme of capillary containing Na reducing agent and the $\mathrm{Na}_{0.66}\left[\mathrm{Li}_{0.22} \mathrm{Ti}_{0.78}\right]_{2} \mathrm{O}_{2}$ sample for the in situ XRD experiment.

Table 1 | Structural parameters.

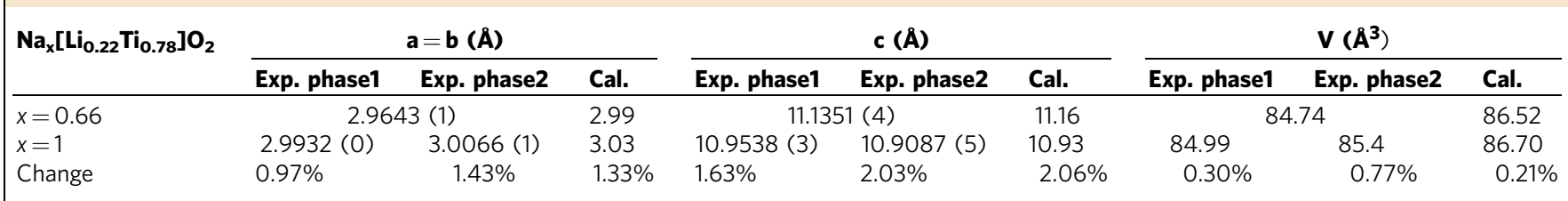

Cal., calculation; DFT, density functional theory; Exp., experiment.

Structural parameters for $\mathrm{P} 2$-type $\mathrm{Na}_{0.66}\left[\mathrm{Li}_{0.22} \mathrm{Ti}_{0.78}\right] \mathrm{O}_{2}$ and $\mathrm{Na}\left[\mathrm{Li}_{0.22} \mathrm{Ti}_{0.78}\right] \mathrm{O}_{2}$ obtained from experiments and DFT calculations.

expanded by $1.43 \%$ after $\mathrm{Na}$ insertion, which are in good agreement with DFT calculations. The trend of the change of the lattice parameter during discharge and charge is similar to a typical layered $\mathrm{LiCoO}_{2}$. The Coulomb attraction between inserted alkali metal ions and TM layers draws the neighbouring TM layers closer, and the larger ion size of the more reduced TM cations causes the expanded TM-O bond. Nevertheless, the unit-cell volume change before and after sodium insertion is $\sim 0.77 \%$, which is close to zero-strain characteristics. It should be noted that this small volume change is originated from the lattice parameter changes in the opposite directions ( $a$ and $b$ expand, whereas $c$ contracts during $\mathrm{Na}$ insertion). This would effectively ensure the structural stability of the electrode during cycling, leading to an excellent long cycle life as demonstrated by over 1,200 cycles. It should be mentioned that this is the first zero-strain negative electrode material for long-life sodium-ion batteries.

No capacity contribution originating from the migration of $\mathrm{Li}^{+}$ions from the TM sites is observed in the experiment. Although the radii of $\mathrm{Li}^{+}$ions is smaller than that of $\mathrm{Na}^{+}$ions, the path connecting two $\mathrm{Li}^{+}$sites is through the $\mathrm{TiO}_{6}$ octahedra in which the space is too small to accommodate a $\mathrm{Li}^{+}$ion. For this reason, the migration of $\mathrm{Li}^{+}$ions within the $\left[\mathrm{Li}_{0.22} \mathrm{Ti}_{0.78}\right] \mathrm{O}_{2}$ layer will not occur. The $\mathrm{Li}^{+}$ion diffusion from TM layer to the $\mathrm{Na}$ layer is also difficult according to the calculated migration energy barrier as shown in Fig. 6 . The energy barrier for $\mathrm{Li}^{+}$ions 

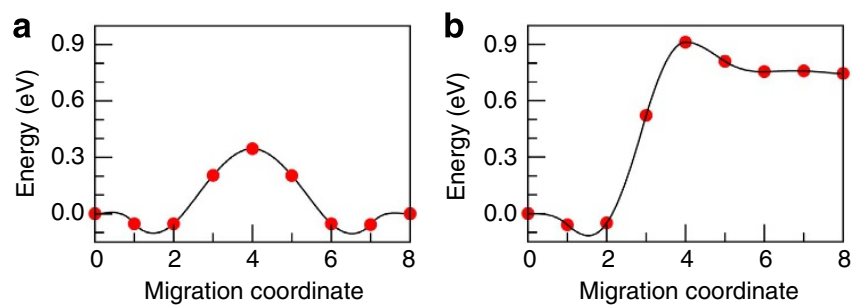

Figure 6 | DFT calculations. The calculated migration energy barrier of the single vacancy assisted (a) $\mathrm{Na}^{+}$ion diffusion in the $\mathrm{Na}$ layer, and (b) $\mathrm{Li}^{+}$ ion diffusion from the transition metal layer to the Na layer in P2-

$\mathrm{Na}\left[\mathrm{Li}_{\mathrm{O} .33} \mathrm{Ti}_{\mathrm{O} .67}\right] \mathrm{O}_{2}$.

leaving the TM layer is $\sim 1 \mathrm{eV}$, whereas the activation energy for $\mathrm{Na}^{+}$ion diffusion within the $\mathrm{Na}$ layer is only $\sim 0.4 \mathrm{eV}$. Accordingly, the estimated diffusion coefficient is $\sim 5.9 \times 10^{-20}$ $\mathrm{cm}^{-2} \mathrm{~s}^{-1}$ for $\mathrm{Li}^{+}$and $\sim 2.1 \times 10^{-10} \mathrm{~cm}^{-2} \mathrm{~s}^{-1}$ for $\mathrm{Na}^{+}$, indicating that the migration of $\mathrm{Li}^{+}$ions can be ignored compared with that of $\mathrm{Na}^{+}$ions (experimental results are shown in Supplementary Fig. S9). Besides the large energy barrier for $\mathrm{Li}^{+}$migration, the occupation of $\mathrm{Li}$ at $\mathrm{Na}$ site will increase the total energy of the system by $\sim 0.8 \mathrm{eV}$ (Fig. $6 \mathrm{~b}$ ), indicating that the migration of $\mathrm{Li}^{+}$ions into $\mathrm{Na}$ layer is energetically unfavourable. This can be understood by the different ionic radii of $\mathrm{Li}^{+}$and $\mathrm{Na}^{+}$. This is also supported by the fact that no any $\mathrm{Li}$ can be detected from the electrolyte and the sodium electrode according to ICP experiment. The occupation of $\mathrm{Li}^{+}$with smaller radii at the $\mathrm{Na}$ site will cause obvious local strain and thus increase the energy of whole system. The detailed migration pathways of $\mathrm{Na}^{+}$ions are analysed using DFT calculations, and the diffusion kinetics comparison between P2- and O3-type structures are shown in Supplementary Fig. S10 and Fig. S11, which further prove that the trigonal prismatic environment is much more beneficial for the migration of $\mathrm{Na}^{+}$ions.

In summary, the P2-type layered $\mathrm{Na}_{0.66}\left[\mathrm{Li}_{0.22} \mathrm{Ti}_{0.78}\right] \mathrm{O}_{2}$ shows a reversible capacity of $116 \mathrm{mAh} \mathrm{g}^{-1}$ at an average storage voltage of $0.75 \mathrm{~V}$ which is far from the sodium plating voltage, making the battery potentially safer. The most important appealing feature is the zero-strain characteristics of this material during sodium insertion/extraction, which ensures the long cycle life as demonstrated by over 1,200 cycles with a very small capacity decay of $0.02 \%$ per cycle, representing the best cyclic performance so far among all the reported negative electrode materials for sodium-ion batteries. In addition, this P2-type layered material exhibits an unusual quasi-single-phase electrochemical storage behaviour which is in contrast to most of other P2-type materials. We believe that these findings obtained here open a new avenue in the search of even better negative electrode materials and will be helpful in speeding up the development of room-temperature long-life sodium-ion batteries for large-scale energy storage systems.

\section{Methods}

Synthesis. The resulting material was prepared by a solid-state reaction using precursors of $\mathrm{Li}_{2} \mathrm{CO}_{3}(99 \%), \mathrm{Na}_{2} \mathrm{CO}_{3}(99 \%)$ and $\mathrm{TiO}_{2}$ (99.5\%, anatase form). A phase-pure compound was obtained when an excess of $2 \mathrm{~mol} \% \mathrm{Li}_{2} \mathrm{CO}_{3}$ and $\mathrm{Na}_{2} \mathrm{CO}_{3}$ was used. The starting materials were ground in an agate mortar and pressed into pellets under pressure of $20 \mathrm{MPa}$. Then the pellets were heated at $1000^{\circ} \mathrm{C}$ for $24 \mathrm{~h}$ in an alumina crucible.

Characterizations. The morphologies of the materials were investigated using a scanning electron microscope (Hitachi S-4800) and a transmission electron microscope (Tecnai $G^{2}$ F20 U-TWIN). The XRD patterns were collected in a transition mode at beamline X14A of National Synchrotron Light Source (NSLS, $\mathrm{BNL}$ ) by a linear position-sensitive silicon detector. The wavelength used was
0.7784 Å. For in situ XRD experiment during electrochemical cycling, CR2032 coin-type cell was used with a glassy carbon window for X-ray penetration; for in situ XRD experiment during chemical sodiation according to our recent work that will be published elsewhere. A total of $0.6 \mathrm{mg} \mathrm{Na} \mathrm{Na}_{0.66} \mathrm{Li}_{0.22} \mathrm{Ti}_{0.78} \mathrm{O}_{2}$ powder dispersed with cotton was loaded into a glass capillary $(0.7 \mathrm{~mm}$ in diameter), then, $0.01 \mathrm{ml}$ sodium-biphenyl-DME solution ( $1 \mathrm{~mol} \mathrm{Na}$ : $1 \mathrm{~mol}$ biphenyl per litre of DME solution) was injected into the capillary. The open end of the capillary was quickly sealed and the capillary was immediately transferred to the synchrotron beamline for in situ experiment. All the operations were carefully performed in the argon-filled glove box. Structures were refined using the Rietveld method as implemented in the TOPAS software package (version 4.1). The background was estimated by chebyshev polynomials. The atomic displacement parameters (ADP or Biso) were fixed to reasonable values $\left(1.0,0.5,0.5\right.$ and $0.8 \AA^{2}$ for sodium, titanium, lithium and oxygen, respectively).

Electrochemistry. The working electrode was prepared by spreading the slurry of the active materials (60 wt\%), acetylene black (30 wt\%) and the polyvinylidene fluoride $(10 \mathrm{wt} \%)$ binder on $\mathrm{Cu}$ foil. The working electrodes were dried at $100{ }^{\circ} \mathrm{C}$ under vacuum for $10 \mathrm{~h}$. The electrolyte is $1 \mathrm{M} \mathrm{NaClO}_{4}$ in EC:DEC (4:6 in volume). The coin-type (CR2032) cells were assembled with pure sodium foil as the counter electrode, and a glass fibre as the separator in an argon-filled glove box. The charge and discharge measurements were carried out on a Land BT2000 battery test system (Wuhan, China) in a voltage range of $0.4-2.5 \mathrm{~V}$ under room temperature and $60^{\circ} \mathrm{C}$. A sodium-ion full cell was constructed using $\mathrm{Na}_{0.66}\left[\mathrm{Li}_{0.22} \mathrm{Ti}_{0.78}\right] \mathrm{O}_{2}$ as the negative electrode and $\mathrm{Na}_{3} \mathrm{~V}_{2}\left(\mathrm{PO}_{4}\right)_{3} / \mathrm{C}$ as the positive electrode in a CR2032 cointype cell. The $\mathrm{Na}_{0.66}\left[\mathrm{Li}_{0.22} \mathrm{Ti}_{0.78}\right] \mathrm{O}_{2}$ electrode was prepared as shown in the above part, and the $\mathrm{Na}_{3} \mathrm{~V}_{2}\left(\mathrm{PO}_{4}\right)_{3} / \mathrm{C}$ electrode was prepared according to our previous report. The weight ratio of the two electrodes (negative/positive) was 1:1.8. The electrolyte solution was $1 \mathrm{M} \mathrm{NaPF}_{6}$ in EC:DEC (4:6 in volume). The full cells were charged and discharged between the voltage range of $1.6-3.0 \mathrm{~V}$ at various C-rates $\left(\mathrm{C} / 10\right.$ current rate corresponds to $\left.10.6 \mathrm{~mA} \mathrm{~g}^{-1}\right)$. Supplementary Fig. S12 shows the first charge/discharge profile of the full cell at a current rate of $\mathrm{C} / 10$.

DFT calculations. The calculations were performed with the Vienna ab initio simulation package. The present data were obtained using the spin-polarized generalized gradient approximation with a parameterized exchange-correlation functional according to Perdew-PBE. The $\mathrm{Na}(2 p, 3 s), \operatorname{Li}(1 s, 2 s, 2 p), \mathrm{Ti}(3 d, 4 s)$ and $\mathrm{O}(2 s, 2 p)$ orbital are treated as valence states. The cutoffs for the wave function and density are $500 \mathrm{eV}$ and $756 \mathrm{eV}$, respectively. The energy barriers of diffusion pathways were calculated by the nudged elastic band method with the energy and force convergence criterion $10^{-5} \mathrm{eV}^{-1}$ and $0.01 \mathrm{eV}^{-1}$, respectively.

\section{References}

1. Yang, Z. et al. Electrochemical energy storage for green grid. Chem. Rev. 111, 3577-3613 (2011).

2. Dunn, B., Kamath, H. \& Tarascon, J. M. Electrical energy storage for the grid: a battery of choices. Science 334, 928-935 (2011).

3. Wessells, C. D., Huggins, R. A. \& Cui, Y. Copper hexacyanoferrate battery electrodes with long cycle life and high power. Nat. Commun. 2, 550 (2011).

4. Pasta, M., Wessells, C. D., Huggins, R. A. \& Cui, Y. A high-rate and long cycle life aqueous electrolyte battery for grid-scale energy storage. Nat. Commun. 3, 1149 (2012)

5. Suo, L., Hu, Y.-S., Li, H., Armand, M. \& Chen, L. A new class of solvent-in-salt electrolyte for high-energy rechargeable metallic lithium batteries. Nat. Commun. 4, 1481 (2013).

6. Armand, M. \& Tarascon, J. M. Building better batteries. Nature 451, 652-657 (2008).

7. Ellis, B. L., Makahnouk, W. R. M., Makimura, Y., Toghill, K. \& Nazar, L. F. A multifunctional $3.5 \mathrm{~V}$ iron-based phosphate cathode for rechargeable batteries. Nat. Mater. 6, 749-753 (2007).

8. $\mathrm{Zu}, \mathrm{C} . \mathrm{X} . \& \mathrm{Li}, \mathrm{H}$. Thermodynamic analysis on energy densities of batteries. Energy Environ. Sci. 4, 2614-2624 (2011).

9. Palomares, V. et al. Na-ion batteries, recent advances and present challenges to become low cost energy storage systems. Energy Environ. Sci. 5, 5884-5901 (2012).

10. Kim, S.-W., Seo, D.-H., Ma, X., Ceder, G. \& Kang, K. Electrode Materials for Rechargeable Sodium-Ion Batteries: Potential Alternatives to Current LithiumIon Batteries. Adv. Energy Mater. 2, 710-721 (2012).

11. Slater, M. D., Kim, D., Lee, E. \& Johnson, C. S. Sodium-Ion Batteries. Adv. Funct. Mater. 947-958 (2012).

12. Ellis, B. L. \& Nazar, L. F. Sodium and sodium-ion energy storage batteries. Curr. Opin. Solid State Mater. Sci. 16, 168-177 (2012).

13. Jian, Z. L. et al. Carbon coated Na3V2(PO4)(3) as novel electrode material for sodium ion batteries. Electrochem. Commun. 14, 86-89 (2012).

14. Jian, Z. et al. Superior electrochemical performance and storage mechanism of Na3V2(PO4)3 cathode for room-temperature sodium-ion batteries. Adv. Energy Mater. 3, 156-160 (2013). 
15. Cao, Y. et al. Reversible sodium ion insertion in single crystalline manganese oxide nanowires with long cycle life. Adv. Mater. 23, 3155-3160 (2011).

16. Lu, Y., Wang, L., Cheng, J. \& Goodenough, J. B. Prussian blue: a new framework of electrode materials for sodium batteries. Chem. Commun. 48, 6544-6546 (2012)

17. Ong, S. P. et al. Voltage, stability and diffusion barrier differences between sodium-ion and lithium-ion intercalation materials. Energy Environ. Sci. 4, 3680-3688 (2011).

18. Hayashi, A., Noi, K., Sakuda, A. \& Tatsumisago, M. Superionic glass-ceramic electrolytes for room-temperature rechargeable sodium batteries. Nat. Commun. 3, 856 (2012).

19. Li, Z., Young, D., Xiang, K., Carter, W. C. \& Chiang, Y.-M. Towards high power high energy aqueous sodium-ion batteries: The NaTi2(PO4)3/Na0.44MnO2 System. Adv. Energy Mater. 290-294 (2012).

20. Abouimrane, A. et al. Sodium insertion in carboxylate based materials and their application in 3.6 V full sodium cells. Energy Environ. Sci. 5, 9632-9638 (2012).

21. Ponrouch, A., Marchante, E., Courty, M., Tarascon, J.-M. \& Palacin, M. R. In search of an optimized electrolyte for Na-ion batteries. Energy Environ. Sci. 5, 8572-8583 (2012)

22. Barpanda, P. et al. Sodium iron pyrophosphate: A novel $3.0 \mathrm{~V}$ iron-based cathode for sodium-ion batteries. Electrochem. Commun. 24, 116-119 (2012).

23. Shakoor, R. A. et al. A combined first principles and experimental study on Na3V2(PO4)2F3 for rechargeable Na batteries. J. Mater. Chem. 22, 20535-20541 (2012).

24. Qian, J., Zhou, M., Cao, Y., Ai, X. \& Yang, H. Nanosized Na4Fe(CN)6/C composite as a low-cost and high-rate cathode material for sodium-ion batteries. Adv. Energy Mater. 2, 410-414 (2012).

25. Ferg, E., Gummow, R. J., Dekock, A. \& Thackeray, M. M. Spinel anodes for lithium-ion batteries. J. Electrochem. Soc. 141, L147-L150 (1994).

26. Ohzuku, T., Ueda, A. \& Yamamoto, N. Zero-strain insertion material of LiLi1/ 3Ti5/3O4 for rechageable lithiun cells. J. Electrochem. Soc. 142, 1431-1435 (1995).

27. Zhao, L., Hu, Y. S., Li, H., Wang, Z. \& Chen, L. Porous Li4Ti5O12 coated with $\mathrm{N}$-doped carbon from ionic liquids for Li-ion batteries. Adv. Mater. 23, 1385-1388 (2011).

28. Komaba, S. et al. Electrochemical $\mathrm{Na}$ Insertion and Solid Electrolyte Interphase for Hard-Carbon Electrodes and Application to Na-Ion Batteries. Adv. Funct. Mater. 21, 3859-3867 (2011).

29. Alcantara, R., Jaraba, M., Lavela, P. \& Tirado, J. L. NiCo2O4 spinel: First report on a transition metal oxide for the negative electrode of sodium-ion batteries. Chem. Mater. 14, 2847-2848 (2002).

30. Senguttuvan, P., Rousse, G., Seznec, V., Tarascon, J. M. \& Palacin, M. R. Na2Ti3O7: lowest voltage ever reported oxide insertion electrode for sodium ion batteries. Chem. Mater. 23, 4109-4111 (2011)

31. Xiong, H., Slater, M. D., Balasubramanian, M., Johnson, C. S. \& Rajh, T. Amorphous $\mathrm{TiO} 2$ nanotube anode for rechargeable sodium ion batteries. J. Phys. Chem. Lett. 2, 2560-2565 (2011).

32. Sun, Y. et al. Direct atomic-scale confirmation of three-phase storage mechanism in Li4Ti5O12 anodes for room-temperature sodium-ion batteries. Nat. Commun. 4, 1870 (2013).

33. Sun, Q., Ren, Q. Q., Li, H. \& Fu, Z. W. High capacity Sb2O4 thin film electrodes for rechargeable sodium battery. Electrochem. Commun. 13, 1462-1464 (2011).

34. Qian, J. F. et al. High capacity Na-storage and superior cyclability of nanocomposite $\mathrm{Sb} / \mathrm{C}$ anode for Na-ion batteries. Chem. Commun. 48, 7070-7072 (2012).

35. Xiao, L. F. et al. High capacity, reversible alloying reactions in $\mathrm{SnSb} / \mathrm{C}$ nanocomposites for Na-ion battery applications. Chem. Commun. 48, 3321-3323 (2012).

36. Zhao, L. et al. Disodium terephthalate $(\mathrm{Na} 2 \mathrm{C} 8 \mathrm{H} 4 \mathrm{O} 4)$ as high performance anode material for low-cost room-temperature sodium-ion battery. Adv. Energy Mater. 2, 962-965 (2012).

37. Il Park, S., Gocheva, I., Okada, S. \& Yamaki, J. Electrochemical properties of $\mathrm{NaTi} 2(\mathrm{PO} 4)(3)$ anode for rechargeable aqueous sodium-ion batteries. J. Electrochem. Soc. 158, A1067-A1070 (2011).

38. Senguttuvan, P. et al. Low-potential sodium insertion in a NASICON-type structure through the Ti(III)/Ti(II) redox couple. J. Am. Chem. Soc. 135, 3897-3903 (2013).

39. Chevrier, V. L. \& Ceder, G. Challenges for Na-ion negative electrodes I. Electrochem. Soc. 158, A1011-A1014 (2011)

40. Stevens, D. A. \& Dahn, J. R. High capacity anode materials for rechargeable sodium-ion batteries. J. Electrochem. Soc. 147, 1271-1273 (2000).

41. Wenzel, S., Hara, T., Janek, J. \& Adelhelm, P. Room-temperature sodium-ion batteries: improving the rate capability of carbon anode materials by templating strategies. Energy Environ. Sci. 4, 3342-3345 (2011).

42. Delmas, C., Braconnier, J.-J., Fouassier, C. \& Hagenmuller, P. Electrochemical intercalation of sodium in $\mathrm{NaxCoO} 2$ bronzes. Solid State Ionics 3-4, 165-169 (1981).
43. Komaba, S., Takei, C., Nakayama, T., Ogata, A. \& Yabuuchi, N. Electrochemical intercalation activity of layered $\mathrm{NaCrO} 2$ vs. LiCrO2. Electrochem. Commun. 12, 355-358 (2010)

44. Berthelot, R., Carlier, D. \& Delmas, C. Electrochemical investigation of the P2-NaxCoO2 phase diagram. Nat. Mater. 10, 74-U73 (2011).

45. Kim, D. et al. Layered Na Ni1/3Fe1/3Mn1/3 O-2 cathodes for Na-ion battery application. Electrochem. Commun. 18, 66-69 (2012).

46. Yabuuchi, N. et al. P2-type Na-x Fe1/2Mn1/2 O-2 made from earth-abundant elements for rechargeable Na batteries. Nat. Mater. 11, 512-517 (2012).

47. Kim, D. et al. Enabling sodium batteries using lithium-substituted sodium layered transition metal oxide cathodes. Adv. Energy Mater. 1, 333-336 (2011).

48. Guignard, M. et al. P2-NaxVO2 system as electrodes for batteries and electroncorrelated materials. Nat. Mater. 12, 74-80 (2013).

49. Carlier, D. et al. The $\mathrm{P} 2-\mathrm{Na} 2 / 3 \mathrm{Co} 2 / 3 \mathrm{Mn} 1 / 3 \mathrm{O} 2$ phase: structure, physical properties and electrochemical behavior as positive electrode in sodium battery. Dalton. Trans. 40, 9306-9312 (2011).

50. Sathiya, M., Hemalatha, K., Ramesha, K., Tarascon, J. M. \& Prakash, A. S. Synthesis, structure, and electrochemical properties of the layered sodium insertion cathode material: NaNil/3Mn1/3Co1/3O2. Chem. Mater. 24, 1846-1853 (2012).

51. Komaba, S. et al. Study on the reversible electrode reaction of $\mathrm{Na1}$ $\mathrm{xNi} 0.5 \mathrm{Mn} 0.5 \mathrm{O} 2$ for a rechargeable sodium-ion battery. Inorg. Chem. 51, 6211-6220 (2012).

52. Yoshida, H., Yabuuchi, N. \& Komaba, S. NaFe0.5Co0.5O2 as high energy and power positive electrode for $\mathrm{Na}$-ion batteries. Electrochem. Commun. 34, 60-63 (2013).

53. Delmas, C., Fouassier, C. \& Hagenmuller, P. Structural classification and properties of the layered oxides. Physica B+C 99, 81-85 (1980).

54. Maazaz, A., Delmas, C. \& Hagenmuller., D. A study of the NaxTiO2 system by electrochemical deintercalation. J. Incl. Phenom. 1, 45-51 (1983).

55. Shilov, G. V., Nalbandyan, V. B., Volochaev, V. A. \& Atovmyan, L. O. Crystal growth and crystal structures of the layered ionic conductors-sodium lithium titanium oxides. Int. J. Inorg. Mater. 2, 443-449 (2000).

56. De Boisse, B. M., Carlier, D., Guignard, M. \& Delmas, C. Structural and electrochemical characterizations of P2 and New O3-NaxMn1-yFeyO2 Phases prepared by auto-combustion synthesis for $\mathrm{Na}$-ion batteries. J. Electrochem. Soc 160, A569-A574 (2013).

57. Komaba, S. et al. Fluorinated ethylene carbonate as electrolyte additive for rechargeable NA batteries. ACS Appl. Mater. Interfaces 3, 4165-4168 (2011).

58. Ehrenberg, H. et al. The crystal and magnetic structure relationship in $\mathrm{Cu}(\mathrm{W}-1-\mathrm{xMOx}) \mathrm{O}-4$ compounds with wolframite-type structure J. Phys.-Condes. Mat. 14, 8573-8581 (2002).

59. Pan, H. et al. Sodium Storage and transport properties in layered $\mathrm{Na}_{2} \mathrm{Ti}_{3} \mathrm{O}_{7}$ for room-temperature sodium-ion batteries. Adv. Energy Mater. doi:10.1002/aenm.201300139 (2013).

\section{Acknowledgements}

We thank Professor C. Delmas for the helpful and valuable discussions on the structure evolution during sodium insertion. This work was supported by funding from the ' 863 ' Project (2011AA11A235, 2009AA03310), '973' Projects (2009CB220104, 2010CB833102, 2012CB932900), NSFC $(51222210,11234013)$, CAS project (KJCX2-YW-W26) and One Hundred Talent Project of the Chinese Academy of Sciences. The work at Brookhaven National Laboratory is supported by the US Department of Energy, the Assistant Secretary for Energy Efficiency and Renewable Energy, Office of Vehicle Technologies under Contract Number DEAC02-98CH10886. We also acknowledge beamline X14A and X18A at NSLS (BNL) and Shanghai Synchrotron Radiation Facility (SSRF) BL14B1.

\section{Author contributions}

Y.-S.H. designed this work; Y.W. carried out the electrochemical experiment; S.X. and Y.W. constructed a full battery and obtained ICP results; X.Y. and Y.W. performed in situ and ex situ XRD measurements with X.-Q.Y.; X.Y. and J.B. refined the XRD results with X.-Q.Y.; R.X. performed the first principles calculations, Y.-S.H., R.X. and Y.W. wrote the paper; all the authors participated in analysis of the experimental data and discussions of the results as well as preparing the paper.

\section{Additional information}

Supplementary Information accompanies this paper at http://www.nature.com/ naturecommunications

Competing financial interests: The authors declare no competing financial interests

Reprints and permission information is available online at http://npg.nature.com/ reprintsandpermissions/

How to cite this article: Wang, $\mathrm{Y}$, et al. A zero-strain layered metal oxide as the negative electrode for long-life sodium-ion batteries. Nat. Commun. 4:2365 doi: $10.1038 /$ ncomms3365 (2013) 


\section{Erratum: A zero-strain layered metal oxide as the negative electrode for long-life sodium-ion batteries}

Yuesheng Wang, Xiqian Yu, Shuyin Xu, Jianming Bai, Ruijuan Xiao, Yong-Sheng Hu, Hong Li, Xiao-Qing Yang, Liquan Chen \& Xuejie Huang

Nature Communications 4:2365 doi:10.1038/ncomms3365 (2013); Published 27 Aug 2013; Updated 3 Dec 2013

The images in Supplementary Fig. S9 are missing in this Article. The figure as it should have been published appears below.
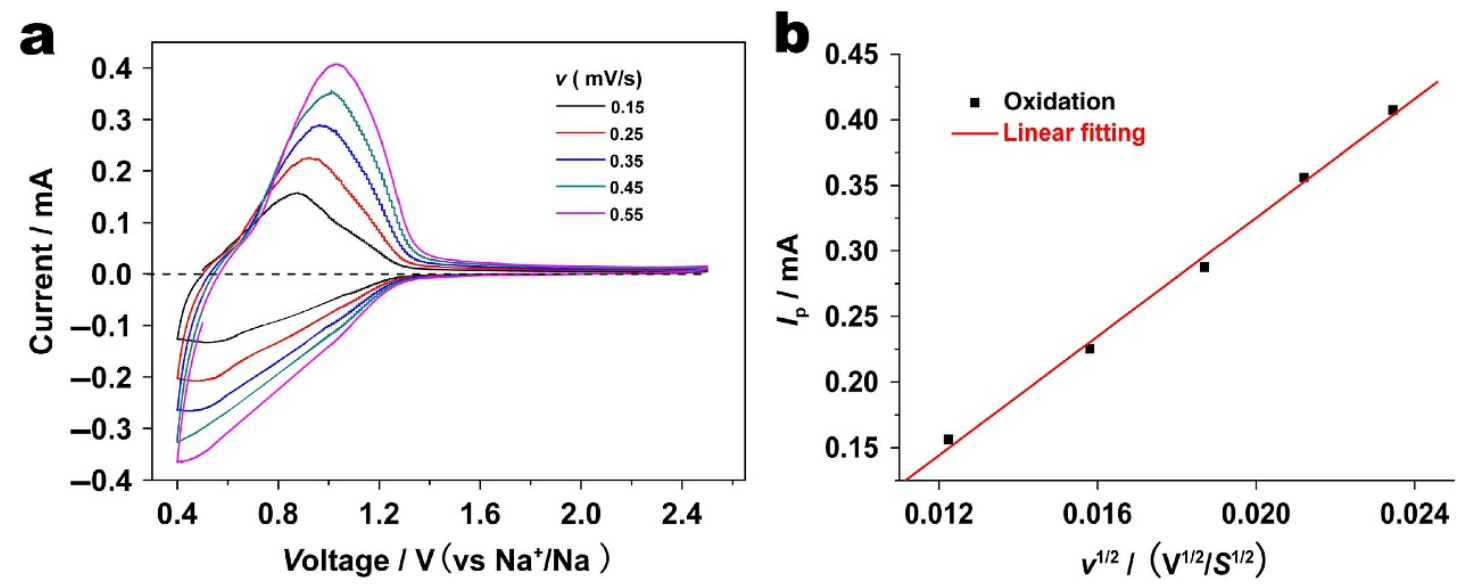

Supplementary Figure S9 $\mid \mathrm{Na}^{+}$ion diffusion. $\mathrm{Na}^{+}$ion diffusion kinetics in $\mathrm{P} 2-\mathrm{Na}_{0.66}\left[\mathrm{Li}_{0.22} \mathrm{Ti}_{0.78}\right] \mathrm{O}_{2}$. (a) Cyclic voltammograms of the $\mathrm{P} 2-\mathrm{Na}_{0.66}\left[\mathrm{Li}_{0.22} \mathrm{Ti}_{0.78}\right] \mathrm{O}_{2}$ electrodes at various scan rates, and (b) Relationship between peak current $I p$ and square root of scan rate $v^{1 / 2}$. The $\mathrm{Na}^{+}$ion diffusion coefficient was calculated to be $\sim 1 \times 10^{-10} \mathrm{~cm}^{2} \mathrm{~s}^{-1}$. 